\title{
Effects of Ventromedial Hypothalamic Lesions on Adipose Tissue of Weanling Male Rats
}

\author{
J. K. Goldman, L. L. Bernardis, R. G. MacKenzie, M. Kodis, and R. Luboshitzky \\ Buffalo Veterans Administration Medical Center, State University of New York, Buffalo, New York, USA
}

Summary. In weanling male rats, destruction of the ventromedial hypothalamus causes increased carcass lipid deposition and decreased linear growth without changes in food intake or blood glucose levels. These changes are not dependent on altered pituitary function. Lipogenesis and glucose utilization are increased in vivo and in vitro, while gluconeogenesis is accelerated in vivo. The enhanced lipogenesis occurs before increased gluconeogenesis.

Key words: Obesity, hypothalamus, lipogenesis, gluconeogenesis

This review will deal almost exclusively with the known effects of ventromedial hypothalamic lesions (VMHL) on carbohydrate and lipid metabolism of adipose tissue. It will not discuss changes in pancreatic secretion, hepatic metabolism or feeding behavior except where necessary. Several review articles on experimental obesity have appeared recently $[1,2,3,4,5,6]$, and the reader interested in a broader discussion of this subject should consult them.

In this review obesity will be defined as an excess of body fat, either absolute or relative to total body weight.

The experimental study of hypothalamic obesity began in 1939 with the work of Hetherington and Ranson [7]. Their data showed that mature VMHL rats developed hyperphagia and then obesity. This led quite logically to the hypothesis that VMHL rats had a primary defect in sensing satiety, and that hyperphagia was responsible for the development of adiposity [8] and the more recently noted hyperinsulinaemia [9].

However, within the past 15 years a large number of studies have demonstrated that this model is not sufficient to explain hypothalamic obesity. In 1965 Han and coworkers $[10,11]$ observed that weanling
VMHL rats developed obesity and impaired linear growth without any increase in food intake. This syndrome was accompanied by decreased physical activity and oxygen consumption, but the decreased activity was not sufficient to explain either the decreased oxygen consumption or the accretion of adipose tissue [12]. Furthermore, although growth hormone deficiency was a concomitant of the syndrome, pituitary dysfunction was neither sufficient nor necessary for the syndrome to develop $[13,14]$. Further observations documented direct effects of the hypothalamus on autonomic nervous system function with subsequent changes in insulin secretion and hepatic carbohydrate metabolism $[3,5]$. These findings resulted in development of a model of hypothalamic obesity in which hyperinsulinaemia was primary $[1,15]$. Based on this model studies on changes in adipose tissue structure and function in VMHL rats began in the late 1960's and have continued to the present.

\section{Body Composition}

Mature VMHL rats have increased weight gain due exclusively to the deposition of lipid, and the adipose tissue deposits of these animals are greatly enlarged. This increased adiposity is not dependent on hyperphagia, however, since even restricted or pair-feeding does not prevent increases in adipose tissue [16]. In weanling VMHL rats that are not hyperphagic, similar changes occur [14]. In these latter rats a concomitant diminution in protein accretion occurs [14, 16] as an expression of impaired nitrogen retention and abnormal protein metabolism $[17,18]$. The increase in adipose tissue mass is primarily due to adipocyte enlargement rather than proliferation. Table 1 contains previously unpublished data obtained in collaboration with Dr. Lester Salans in support of this contention. 
Table 1. Fat pad composition in weanling rats with hypothalamic obesity

\begin{tabular}{lcc}
\hline & Control [7] & Lesion [5] \\
\hline mg lipid $/ 10^{6}$ cells & $56 \pm 6$ & $244 \pm 21$ \\
mg lipid $/ 2$ pads & $372 \pm 53$ & $1573 \pm 104$ \\
$10^{6}$ cells $/ 2$ pads & $6.5 \pm 0.4$ & $6.5 \pm 0.4$ \\
mg protein $/ 2$ pads & $6.3 \pm 0.1$ & $11.5 \pm 1.0$ \\
mg protein $/ 10^{6}$ cells & $0.99 \pm 0.06$ & $1.79 \pm 0.18$ \\
\hline
\end{tabular}

Table 2. Hexose utilization in VMHL adipocytes

\begin{tabular}{lll}
\hline $\begin{array}{l}\text { Glucose oxidation by VMHL adipocytes } \\
\text { pmol/105 cells/h }\end{array}$ & Lesion \\
\cline { 2 - 3 } & Control & 1272 \\
Basal & 429 & 8813 \\
\hline Insulin & 4244 & \\
\hline 2-deoxyglucose uptake by VMHL adipocytes \\
\multicolumn{3}{c}{ pmol/10 cells/h } \\
\cline { 2 - 3 } & Control & Lesion \\
\hline Basal & 18 & 120 \\
Insulin & 577 & 919 \\
\hline
\end{tabular}

Note: All values corrected for inulin trapping

Table 3. Insulin binding to adipocytes (fmol bound $/ 10^{5}$ cells)

\begin{tabular}{lcr}
\hline Insulin $(\mathrm{mol} / \mathrm{l})$ & Control & Lesion \\
\hline & Total & \\
$0.25 \times 10^{-9}$ & 1.92 & 1.53 \\
$1.0 \times 10^{-9}$ & 5.03 & 5.60 \\
$5.0 \times 10^{-9}$ & 16.69 & 17.28 \\
& & \\
& Non-specific & \\
$0.25 \times 10^{-9}$ & 0.16 & 0.45 \\
$1.0 \times 10^{-9}$ & 0.88 & 1.57 \\
$5.0 \times 10^{-9}$ & 4.42 & 7.11 \\
& & \\
& Specific & 1.08 \\
$0.25 \times 10^{-9}$ & 1.76 & 4.03 \\
$1.0 \times 10^{-9}$ & 4.15 & 10.17 \\
$5.0 \times 10^{-9}$ & 12.27 & \\
\hline
\end{tabular}

\section{Adipose Tissue Glucose Metabolism}

Fat pad segments of obese rats studied in vitro convert more glucose to $\mathrm{CO}_{2}$ and lipids [14]. These findings persist on high fat or fat free diets and are not diminished by $48 \mathrm{~h}$ of fasting prior to sacrifice [19]. These changes first become apparent 4 days after lesion placement in ad libitum fed weanling rats. Hypophysectomy and/or growth hormone adminis- tration in VMHL rats does not significantly alter the obesity of these rats or the enhanced glucose utilization of their adipose tissue. Insulin responsiveness is normal both in vitro [20] and in vivo (see below). Furthermore, fasting did not reduce insulin sensitivity of fat pads from VMHL rats [21].

Glucose utilization by VMHL rat fat pads rises normally with increasing glucose concentrations in vitro. However, it does not plateau at very high concentrations, whereas tissues from normal rats do exhibit a leveling off of glucose utilization [22]. Glucose incorporation into glycogen is not increased in fat pads of VMHL rats [20] suggesting a stimulation of selective pathways of glucose metabolism and indicating that accelerated glucose transport is not fully responsible for the increased utilization seen in VMHL rat tissues.

Isolated adipocytes studied in collaboration with Dr. Dean Lockwood (Table 2) show increased 2deoxyglucose transport and glucose utilization as well as normal responses to added insulin [23]. Likewise, insulin resistance is not seen in epididymal fat pad fragments [20], although slight insulin insensitivity may be present. As a followup to these studies, adipocyte insulin receptors were measured by Dr. Lockwood [23] and found to be normal in terms of numbers of receptors per cell (Table 3 ).

Other in vitro studies have demonstrated increased oxidation of both $1-{ }^{14} \mathrm{C}$ glucose and $6-{ }^{14} \mathrm{C}$ glucose in fat pads of weanling VMHL rats. The data indicated that 1 -carbon oxidation was preferentially increased [22]. Fructose utilization was also increased, whereas pyruvate metabolism was either normal or decreased [22].

Finally in mature VMHL rats similar enhancement of in vitro glucose metabolism was noted whether such rats were pair-fed with controls or allowed to eat ad libitum [16].

In vivo studies were next undertaken to provide a more physiological setting in which substrate availability, hormone milieu and innervation are intact. Intravenously injected ${ }^{14} \mathrm{C}$-glucose disappeared from the blood more rapidly than normal in VMHL rats, and more radioactivity was recovered in tissue lipids of these rats [24]. Following intraperitoneal injection of ${ }^{14} \mathrm{C}$-glucose, incorporation into tissue lipids was similarly increased in VMHL rats, and responded normally to intraperitoneal insulin administration [25].

The importance of hyperinsulinaemia in the syndrome remains unclear. We have shown that either pair-feeding [16] or $48 \mathrm{~h}$ of fasting [19] eliminates hyperinsulinaemia in weanling VMHL rats but does not decrease the accelerated glucose metabolism by fat pad in vitro. Furthermore, preexisting untreated 
diabetes does not eliminate all the differences in carcass lipid content or fat pad glucose metabolism usually seen in VMHL, rats, although these differences were markedly attenuated [26]. In contrast Bray has shown that hyperinsulinaemia and obesity do not develop in mature female VMHL rats if they have been previously rendered diabetic and then had blood glucose and insulin normalized by islet transplantation [27]. In large female rats with diabetes VMH lesions produce the usual hyperphagia but a somewhat attenuated weight gain [28]. Thus, the question of whether hyperinsulinaemia is essential for the development of obesity in VMHL rats remains unanswered.

\section{Adipose Tissue Lipid Metabolism}

Weanling VMHL rats paradoxically have hypertriglyceridemia in the face of elevated adipose tissue lipoprotein lipase activity which responds normally to heparin. Nonetheless, when incubated with plasma containing ${ }^{14} \mathrm{C}$-lipid adipose tissue of VMHL rats took up less radioactivity than normal [29]. Tissues from VMHL rats also released less free fatty acid than normal [30]. Furthermore, glycerol kinase activity was increased in fat pads of VMHL rats [31]. All of these data indicate a decrease in fatty acid uptake and release in the adipose tissue of these rats. Fatty acid synthesis from hexoses is clearly elevated (see above) and fatty acid synthesis as measured by incorporation of tritium from ${ }^{3} \mathrm{H}_{2} \mathrm{O}$ is likewise increased both in vivo (Table 4) and in vitro (Table 5). The in vivo effect is seen within a few hours of lesion production and is apparent in both carcass adipose tissue and liver [32]. Likewise, the enhanced lipogenesis seen in fat pad in vitro is also noted with isolated hepatocytes [33].

\section{Hypothesis}

It is clear that lipogenesis and glucose utilization are increased in VMHL rats, and this phenomenon is independent of hyperphagia or possible pituitary dysfunction. The fact that VMHL rats are normoglycaemic in the face of normal food intake and increased glucose utilization requires an acceleration of gluconeogenesis. Several studies have demonstrated such an acceleration in vivo in a variety of forms of experimental obesity $[2,5,34,35,36,37]$, although studies using perfused liver have not been confirmatory [38]. Perhaps an intact animal preparation is needed either because of neural factors or because of changes in glucose flux which can only be manifest in the whole animal.
Table 4. In vivo lipogenesis in VMHL rats $2-6 \mathrm{~h}$ post-lesion

\begin{tabular}{|c|c|c|c|c|}
\hline \multicolumn{5}{|c|}{$\mu$ mol plasma water incorporated $/ \mathrm{h}$} \\
\hline & \multicolumn{2}{|c|}{ Control } & Lesioned & $\mathrm{P}$ \\
\hline \multicolumn{5}{|l|}{ Liver } \\
\hline $2 \mathrm{~h}$ & \multicolumn{2}{|c|}{$6.4 \pm 0.3$} & $8.4 \pm 0.2$ & $<0.01$ \\
\hline $3 \mathrm{~h}$ & \multicolumn{2}{|c|}{$7.5 \pm 0.9$} & $8.9 \pm 0.6$ & NS \\
\hline $6 \mathrm{~h}$ & \multicolumn{2}{|c|}{$5.6 \pm 8.5$} & $8.5 \pm 1.0$ & $<0.05$ \\
\hline \multicolumn{5}{|l|}{ Carcass } \\
\hline $2 \mathrm{~h}$ & \multicolumn{2}{|c|}{$72 \pm 5$} & $112 \pm 6$ & $<0.01$ \\
\hline $3 \mathrm{~h}$ & \multicolumn{2}{|c|}{$78 \pm 9$} & $111 \pm 9$ & $<0.05$ \\
\hline $6 \mathrm{~h}$ & \multicolumn{2}{|c|}{$27 \pm 2$} & $39 \pm 3$ & $<0.01$ \\
\hline \multicolumn{5}{|c|}{ Overall analysis of variance } \\
\hline \multirow[t]{2}{*}{ Factor } & \multicolumn{2}{|l|}{ Liver } & \multicolumn{2}{|l|}{ Carcass } \\
\hline & F-ratio & $\mathrm{p}$ & F-ratio & $p$ \\
\hline Lesion & 7.11 & $<0.05$ & 22.02 & $<0.01$ \\
\hline Time & 2.37 & NS & 12.70 & $<0.01$ \\
\hline
\end{tabular}

Table 5. In vitro lipogenesis in VMHL fat pads

\begin{tabular}{lccl}
\hline $\begin{array}{l}\text { DPM }{ }^{3} \mathrm{H}_{2} \mathrm{O} \text { incorporated/mg protein } / 3 \mathrm{~h} \\
\text { Conditions }\end{array}$ & Control [6] & Lesioned [9] $\mathrm{p}$ \\
\hline Basal & $13 \pm 2$ & $44 \pm 6$ & $<0.01$ \\
Insulin & $14 \pm 2$ & $40 \pm 3$ & $<0.01$ \\
Glucose $5.5 \mathrm{mmol} / 1$ & $29 \pm 3$ & $77 \pm 12$ & $<0.01$ \\
Glucose + insulin & $154 \pm 10$ & $\mathbf{1 8 1 \pm 2 3}$ & 0.4 (NS) \\
\hline
\end{tabular}

Table 6. Gluconeogenesis in rats with hypothalamic knife-cut induced obesity

uEq plasma $\mathrm{HCO}_{3}^{-}$incorporated

$\begin{array}{ll}\text { Per } \mu \mathrm{mol} & \text { per } \mu \mathrm{g} \\ \text { plasma glucose } & \text { liver glycogen }\end{array}$

Controls (ad lib)

Obese (pair-fed)

$\begin{array}{ll}3.3 \pm 0.5^{\mathrm{a}} & 13.4 \pm 1.7^{\mathrm{c}} \\ 7.3 \pm 1.0^{\mathrm{b}} & 72.3 \pm 8.0^{\mathrm{d}} \\ 4.7 \pm 0.5^{\mathrm{a}} & 24.1 \pm 3.1^{\mathrm{e}}\end{array}$

Values in each column with different superscripts are significantly different from each other

In vivo lipogenesis accelerates before gluconeogenesis after hypothalamic lesions. Thus, one can postulate that increased glucose utilization creates a transient hypoglycaemia which is only subsequently reversed by a compensatory increase in gluconeogenesis. Additional support has recently been obtained in our laboratory by MacKenzie and Luboshitzky. They noted that accelerated gluconeogenesis was seen in rats with hyperphagia and obesity induced by hypothalamic knife cuts, and it became much more apparent when the obese 
rats were limited to normal food intake (Table 6) [39].

The only source for increased glucose production is amino acids. The constant diversion of these into gluconeogenic pathways might well explain the diminished growth and carcass protein content of VMHL rats and the negative nitrogen balance exhibited by these rats.

Thus, finally, one can construct a model of VMHL obesity in which hyperinsulinaemia, increased glucose utilization and increased lipogenesis occur very early. The enhanced glucose disappearance creates a need for extra glucose which is met either by increased food intake or by diversion of amino acid carbon into carbohydrate. Finally, this diversion leads to deficiencies in growth and carcass protein content.

Acknowledgements. The authors wish to express their extreme gratitude to Ms. Renee Chase for secretarial assistance.

The work was supported by VA Medical Research Funds, NIH and NSF grants.

\section{References}

1. Assimacopoulos-Jeannet F, Jeanrenaud B (1976) The hormonal and metabolic basis of experimental obesity. $\mathrm{J}$ Clin Endocrinol Metab 5: 337-365

2. Herberg L, Coleman D (1977) Laboratory animals exhibiting obesity and diabetes syndromes. Metabolism 26: 59-99

3. Woods S, Porte D Jr (1978) The central nervous system, pancreatic hormones, feeding and obesity. Adv Metab Disord 9: 283-312

4. Jeanrenaud B (1979) Insulin and obesity. Diabetologia 17: 133-138

5. Shimazu T (1979) Nervous control of peripheral metabolism. Acta Physiol Pol [Suppl 18] 30: 1-18

6. Bray G, York D (1979) Hypothalamic and genetic obesity in experimental animals: an autonomic and endocrine hypothesis. Physiol Rev 59: 719-809

7. Hetherington A, Ranson S (1939) Experimental hypothalamico-hypophyseal obesity in the rat. Proc Soc Exp Biol Med 41: 465-466

8. Brobeck J (1946) Mechanism of the development of obesity in animals with hypothalamic lesions. Physiol Rev 26: 541-559

9. Hales C, Kennedy G (1964) Plasma glucose, non-esterified fatty acids and insulin concentrations in hypothalamic-hyperphagic rats. Biochem J 90: 620-624

10. Han P, Lin C, Mu J, Liu A-C (1965) Hypothalamic obesity in weanling rats. Am J Physiol 209: 627-631

11. Han P, Liu A-C (1966) Obesity and impaired growth of rats force-fed 40 days after hypothalamic lesions. Am J Physiol 211: $229-231$

12. Han P (1968) Energy metabolism of tube-fed hypophysectomized rats bearing hypothalamic lesions. Am J Physiol 215: $1343-1350$

13. Han P, Frohman L (1970) Hyperinsulinemia in tube-fed hypophysectomized raț bearing hypothalamic lesions. Am J Physiol 219: 1632-1636

14. Goldman J, Schnatz J, Bernardis L, Frohman L (1970) Adipose tissue metabolism of weanling rats after destruction of ventromedial hypothalamic nuclei: effect of hypophysectomy and growth hormone. Metabolism 19: 995-1005
15. Rohner F, Dufour A-C, Karakash C, Le Marchand Y, Ruf K, Jeanrenaud J (1977) Immediate effect of lesion of the ventromedial hypothalamic area upon glucose-induced insulin secretion in anesthetized rats. Diabetologia 13: 239-242

16. Goldman J, Bernardis L, Frohman L (1974) Food intake in hypothalamic obesity. Am J Physiol 227: 88-91

17. Goldman J, Bernardis L (1976) Protein metabolism in weanling rats with hypothalamic obesity. Proc Soc Exp Biol Med 151: $155-159$

18. Holm H, Lovo A, Hustvedt B-E (1978) Protein depletion and energy retention in rats with ventromedial hypothalamic lesions. Nutr Metab 22: 22-31

19. Frohman L, Goldman J, Schnatz J, Bernardis L (1971) Hypothalamic obesity in the weanling rat: effect of diet upon hormonal and metabolic changes. Metabolism 20: 501-512

20. Goldman J, Bernardis L, Frohman L (1972) Insulin responsiveness in vitro of diaphragm and adipose tissue from weanling rats with hypothalamic obesity. Horm Metab Res 4: 328-331

21. Goldman J, Bernardis L (1974) Persistent adipose tissue insulin responsiveness during fasting of weanling rats with hypothalamic obesity. Horm Metab Res 6: 454-456

22. Goldman J, Bernardis L (1974) Metabolism of glucose, fructose and pyruvate in tissues of weanling rats with hypothalamic obesity. Horm Metab Res 6: 370-375

23. Goldman J, Lockwood D, Malchoff D (Accepted for presentation) Volume, insulin binding, and glucose transport and oxidation of adipocytes from normophagic rats with hypothalamic obesity. Endocrine Society Meetings

24. Frohman L, Goldman J, Bernardis L (1972) Metabolism of intravenously injected ${ }^{14} \mathrm{C}$-glucose in weanling rats with hypothalamic obesity. Metabolism 21: 799-805

25. Frohman L, Goldman J, Schnatz J, Bernardis L (1972) Studies of insulin sensitivity in vivo in weanling rats with hypothalamic obesity. Metabolism 21: 1133-1142

26. Goldman J, Schnatz J, Bernardis L, Frohman L (1972) Effects of ventromedial hypothalamic destruction in rats with preexisting streptozotocin-induced diabetes. Metabolism 21: $132-136$

27. Inoue S, Bray G, Mullen Y (1978) Transplantation of pancreatic beta-cells prevents development of hypothalamic obesity in rats. Am J Physiol 235: E 266-E 271

28. Friedman M (1972) Effects of alloxan diabetes on hypothalamic hyperphagia and obesity. Am J Physiol 222: $174-178$

29. Schnatz J, Bernardis L, Frohman L, Goldman J (1971) Hypertriglyceridemia in weanling rats with hypothalamic obesity. Diabetes 20: 655-663

30. Kasemsri S, Bernardis L, Schnatz J (1972) Fat mobilization in adipose tissue of weanling rats with hypothalamic obesity. Horm Res 3: 97-104

31. Kasemsri S, Bernardis L, Chlouverakis C, Schnatz J (1971) The incorporation of ${ }^{14} \mathrm{C}$-glycerol into adipose tissue lipids of weanling rats with hypothalamic obesity. Proc Soc Exp Biol Med 141: 38-42

32. Goldman J, MacKenzie R, Bernardis L, Luboshitzky R, Kodis $\mathrm{M}$ (Submitted for publication) Early metabolic changes following destruction of the ventromedial hypothalamic nuclei

33. Katz J, Wals P, Goldman J, Bernardis L (1977) Lipogenesis by hepatocytes of rats with hypothalamic obesity. Horm Metab Res 9: 59-63

34. Triscari J, Stern J, Johnson P, Sullivan A (1979) Carbohydrate metabolism in lean and obese Zucker rats. Metabolism 28: 183-189

35. Lombardo Y, Menaham L (1979) Gluconeogenesis in perfused livers of genetically obese-hyperglycemic (ob/ob) mice. Horm Metab Res 11: 9-14

36. Felig P, Wahren J, Hendler R, Brundin T (1974) Splanchnic 
glucose and amino acid metabolism in obesity. $J$ Clin Invest 53: $582-590$

37. Goldman J, Bernardis L (1975) Gluconeogenesis in hypothalamic obesity. Horm Metab Res 7: 148-152

38. Karakesh C, Hustvedt B, Lovo A, LeMarchand Y, Jeanrenaud B (1977) Consequences of ventromedial hypothalamic lesions on metabolism of perfused liver. Am J Physiol 232: E 286-293

39. Mackenzie RG, Luboshitzky R, Goldman JK, Bernardis L (in press) Metabolic effects of hypothalamic hyperphagia. Metabolsim

J. K. Goldman, M. D.

Endocrine-Metabolic Section

Veterans Administration Medical Center

3495 Bailey Avenue

Buffalo, NY 14215

USA

\section{Discussion after Goldman's Presentation}

Nicolaidis: The rats you describe with VMHL and hyperinsulinaemia do not seem to resemble the syndrome seen in people with insulinomas. These people are often lean and have hypoglycaemia. Why are they not obese?

Goldman: Actually, I believe most people with insulinomas are actually obese. But I agree with you in that there must be other factors at work in the VMHL obesity than just hyperinsulinaemia. I actually feel that the liver of these animals is going to be insulin resistant in many pathways. Perhaps some of the work of Dr. Shimazu will be very important in the explanation, although I'm not sure that the stimulation studies will provide the entire explanation.

Samols: I would like to make a point. People with insulinomas vary a great deal. They are frequently hyperinsulinaemic only at certain times when gluconeogenesis would normally keep up but can't quite do it, such as in starvation. At that time, they have slightly more insulin than normal. Most of the time, they are normoinsulinaemic. They frequently also have abnormalities of other hormonal systems, so they are not a good model for comparisons.

Goldman: I agree. Olefsky recently reported a study (Diabetologia (1979) 17: 111) with mice given small but progressively larger doses of insulin each day. They greatly resembled the syndrome we observe. These mice were not hypoglycaemic but they were fat. They also had normal numbers of insulin receptors.

Havrankova: Exactly how soon after a lesion of the VMH does the animal become hyperinsulinaemic?

Goldman: That's somewhat controversial. Perhaps we should ask some of those who have looked at this question.

Steffens: First of all, there is an enormous sympathetic arousal right after the lesion is made. Therefore, only after several hours, when this response has lessened, can you see the rise of insulin in awake rats.

Berthoud: Using anesthetized rats, we have seen hyperinsulinaemia within 30 or $40 \mathrm{~min}$, and the response is gone after vagotomy (Endocrinology (1979) 105: 146). Of course, one can never tell whether this response is the same as the hyperinsulinaemia characteristic of the chronic animal, or whether it is perhaps due to some acute irritative effect.

$F$. Jeanrenaud: Do you think that increased glucagon can account for the increased gluconeogenesis of the VMHL syndrome?
Goldman: Well, that certainly may be the explanation in your experiments. However, as you know, we have never observed an increase of glucagon in our weanling rats.

F. Jeanrenaud: I think that perhaps one must sample from the portal vein in order to see the effect.

Nicolaidis: Do you feel that the hyperinsulinaemia is actually the entire syndrome?

Goldman: I can't say for sure. There are a few reports that suggest that streptozotocin- or alloxan-diabetic rats subject to lesioning of the $\mathrm{VMH}$ do get slightly fatter than streptozotocin- or alloxan-diabetic rats not given the lesion. On the other hand, Dr. Bray has some very convincing data suggesting that the syndrome really does not develop in the diabetic animal, or even in the animal with an islet cell transplant. So the syndrome may be totally insulin-dependent or it may not be. I don't think all the answers are in yet. I think that a major metabolic problem of these animals concerns protein metabolism. It's known that the urea levels in the plasma are higher than normal in these rats, and that if you nephrectomize them, their blood urea nitrogen rises much more rapidly than normal, strongly suggesting increased amino acid deamination. One would expect that this carbon skeleton would go either to gluconeogenesis or to lipogenic pathways or both. We are presently turning our attention to the question of amino acid metabolism in these animals. The point is that the changes of amino acid metabolism, if they occur, are not what would be expected given hyperinsulinaemia, so another mechanism would be necessary to account for them.

B. Jeanrenaud: But you must agree that the hyperinsulinaemia seems necessary for the changes in lipid metabolism?

\section{Goldman: Yes.}

Sclafani: How long after you make your lesions thave you measured fat cell number?

Goldman: Around 2 weeks.

Sclafani: At other times, Irving Faust and I have observed a substantial fat cell hyperplasia which you have not reported.

Bray: Yes, but remember that in your experiments, the rats were given a high fat diet, and this may account for the difference. 